\title{
Adapting to climate change impacts in Yap State, Federated States of Micronesia: the importance of environmental conditions and intangible cultural heritage
}

\author{
Reed M. Perkins \\ Department of Environmental Science, Queens University of Charlotte, USA \\ perkinsr@queens.edu
}

\author{
Stefan Michael Krause \\ Department of Humanities, Beacon College, USA \\ skrause@beaconcollege.edu
}

\begin{abstract}
In western Micronesia, sea levels are rising at three to four times the global average, saltwater intrusion is impacting freshwater supplies and food production, and local cultures are being forced to respond. Yap State, Federated States of Micronesia (9.5N, 138E), consists of a cluster of four main islands (MI) and 14 coral atolls and smaller outer islands (OI) spread over $400,000 \mathrm{~km}^{2}$ of ocean. This paper examines three aspects of Yap State's adaptive capacity to climate change impacts: 1) differences in environmental conditions between the MI and OI; 2) relevant features of the MI's cultural heritage; and 3) relevant features of OI's cultural heritage, including values and practices surrounding the sawei system relationship. Cultural support networks in both the MI and OI will almost certainly be relied upon to lessen the severity of climate change impacts, perhaps especially as more OI residents relocate to the MI. More research is needed to document how features of intangible cultural heritage that create and maintain social resilience in Yap State will shape residents' adaptive capacity to climate change.
\end{abstract}

Keywords: adaptive capacity, atolls, climate change, cultural heritage, Pacific, Small Island Developing States (SIDS), Yap

https://doi.org/10.24043/isj.51

(C) 2018 - Institute of Island Studies, University of Prince Edward Island, Canada.

\section{Introduction}

Small Island Developing States (SIDS) are often characterized as particularly vulnerable to the impacts of climate change because of their small populations, limited resources, remoteness, susceptibility to natural disasters, and fragile ecosystems (Nurse et al., 2014; United Nations, 1994). In the tropical western Pacific, sea levels are rising at a rate three to four times the global average (i.e., $10-12 \mathrm{~mm} / \mathrm{yr}$ vs. $3.3 \mathrm{~mm} / \mathrm{yr}$, respectively) (Cazenave \& Remy, 2011), saltwater intrusion is impacting freshwater supplies and food production (Hezel, 2009; Ruegorong et al., unpublished data, 2016; Werner et al., 2017), and beach erosion is a major concern (Hezel, 2009; Keener et al., 2012). Even if rates of sea-level rise in the western Pacific decrease within the next few decades to more closely match global averages (Timmermann et al., 2010), climate change impacts on SIDS are projected to continue through the $21^{\text {st }}$ century (Nurse et al., 2014). Islanders' response to these impacts will strongly influence the long-term viability of human populations and cultures on tropical western Pacific islands. 
A location's vulnerability to climate change is typically defined (e.g., Smit et al., 1999; United Nations Framework Convention on Climate Change [UNFCCC], 2005) as a function of exposure to impact, sensitivity to impact, and adaptive capacity (i.e., the potential, capability, or ability of a system to adapt to climate change stimuli or their effects or impacts). Such a notion is notoriously difficult to define for small islands, in part because of heterogeneity in island geomorphology, culture, ecosystems, and populations (Nurse et al., 2014). For example, Barnett and Campbell (2010) summarize high-elevation islands' exposure to climate change impacts as including coral reef bleaching, flash flooding of streams, and damage from sea-level rise and storms, especially in coastal areas due to concentrations of population and infrastructure. But, high-elevation islands, because of their greater variety and amount of natural resources, are considered less sensitive to climate-related changes than are low-elevation islands (i.e., atolls). Conversely, the latter's extremely small size, coralline soils, and shallow freshwater lenses may result in their being uninhabitable in the next few decades (e.g., Nunn, 2013; Storlazzi et al., 2015). Atoll sensitivity is especially acute in combination with tidal extremes and storm surges, resulting in fresh water shortages and possible human health problems.

Despite general agreement that Pacific islands share many characteristics, there is a paucity of accurate, relevant, and island-specific data (either modeled or empirical) available to quantify the range of unique vulnerabilities of small islands to climate change. Even defining one aspect of vulnerability, for example adaptive capacity, is a complicated task. Park et al. (2012) argue for the need to integrate scientific knowledge, local perceptions of vulnerability, and an accurate understanding of the local ability to successfully respond. Nurse et al. (2014) take this a step further by calling for a consideration of the culturally specific factors driving these local perceptions and abilities. Assessments of adaptive capacity for indigenous island societies may be fundamentally incomplete if they fail to account for the enduring localized cultural adaptations that have developed in response to specific social and ecological challenges. What is needed is a focused approach that acknowledges the uniqueness of individual island cultures and their specific environmental complexities (Allen, 2015).

Yap State, one of four member states (along with Chuuk, Pohnpei, and Kosrae) of the Federated States of Micronesia (FSM) (Figure 1), demonstrates the importance and challenge of considering the full context of resources and pressures when assessing adaptive capacity within a multi-island association. Yap State consists of a cluster of four high islands (Yap's Main Islands, or MI, and often referred to in the literature as 'Yap Proper') and fourteen atolls and small islands (Outer Islands, or OI) distributed over $400,000 \mathrm{~km}^{2}$ of ocean. The MI occupy 9,300 ha with a maximum elevation of $174 \mathrm{~m}$, and are so tightly grouped that they effectively operate as a single land mass. They serve as the centre for virtually all economic and governmental activity within Yap State, and are the location of Yap's banks, hospital, two-year college, and international airport. The OI atolls (e.g., Eauripik, Elato, Faraulep, Gaferut, Ifalik, Lamotrek, Ngulu, Olimarao, Piagailoe, Pikelot, Sorol, Ulithi, Woleai, and Satawal) and one raised coral small island (e.g., Fais) collectively occupy 2,600 ha, with the atolls having a maximum elevation of $5 \mathrm{~m}$. In 2010, Yap State's total population was 11,377 with approximately $65 \%$ living on the MI (FSM Division of Statistics, 2012). Populations in 2010 within individual OI atolls and islands ranged from 26 in Ngulu to 975 in Woleai (FSM Division of Statistics, 2012).

This paper examines three related influences on Yap State's adaptive capacity to climate change impacts: the heterogeneity of the islands' environmental conditions, the relevant aspects of cultural heritage specific to the MI, and aspects specific to the OI, including values and practices surrounding the sawei tribute system relationship between Main Islanders and Outer Islanders. This analysis is based on an examination of relevant literature, as well as the authors' extensive field experience in Yap State beginning in 2000. Research from both authors has included close collaborations and personal interviews with local residents, government officials, and traditional leaders on topics ranging from environmental management to the preservation of cultural heritage. 


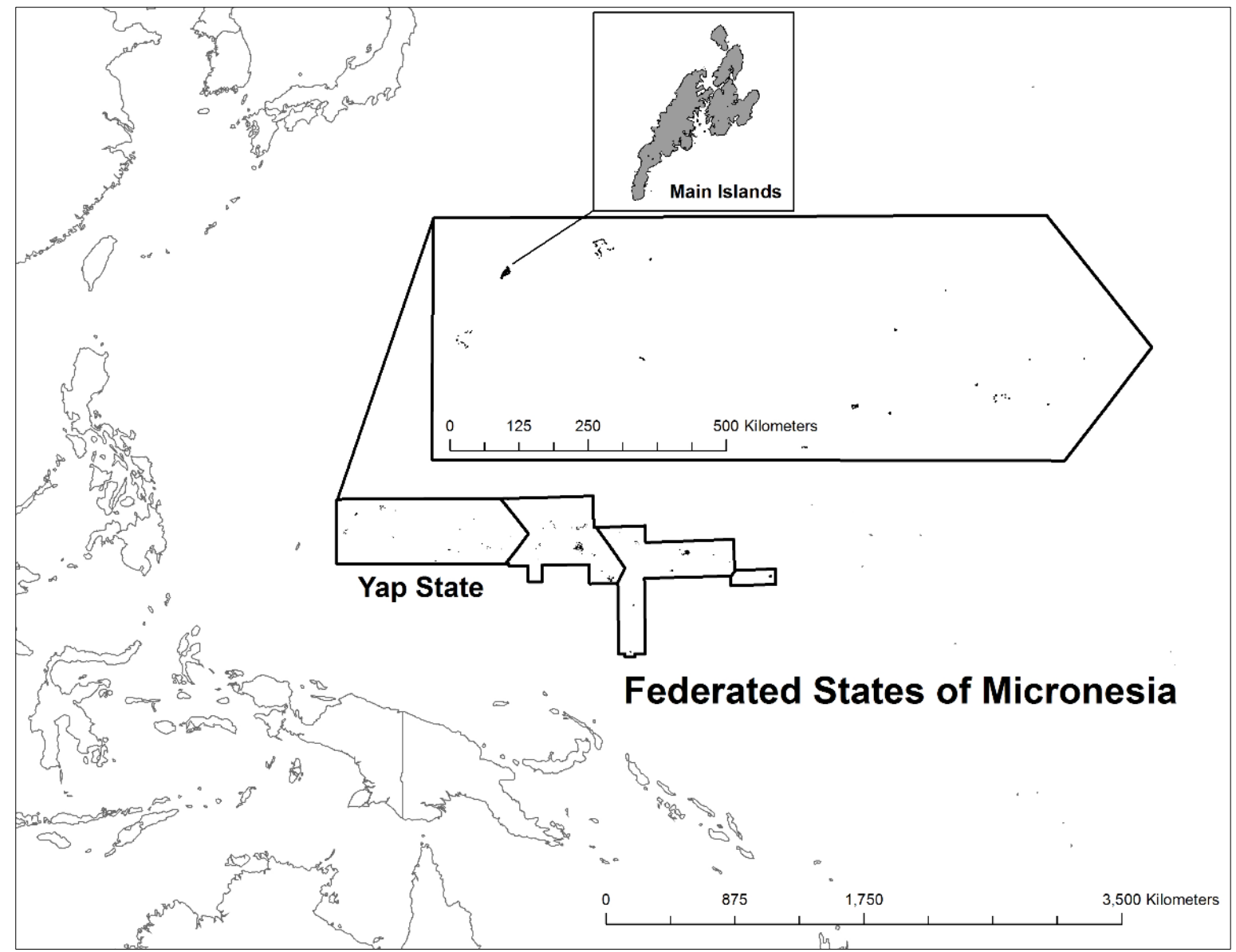

Figure 1: Map showing the Federated States of Micronesia and Yap State in the Pacific. (C) Reed M. Perkins \& Stefan Michael Krause, 2018.

In addition to climatic threats, it is worth noting that FSM islanders also face an uncertain economic future. The USA maintains a defining role in the economic trajectory of the islands through a Compact of Free Association (COFA), originally signed in 1986, then amended in 2003, to support six vital program areas: education, health, infrastructure, publicsector capacity building, and the environment. While the COFA economic assistance is obviously beneficial in many ways, it has also created a relationship of dependency that cannot be ignored. The FSM currently receives approximately US $\$ 130$ million per year from the USA ('US Relations with the FSM', 2017), or approximately 58\% of total national revenues. Roughly two-thirds of employees nationwide work for the government (CIA World Factbook, 2017), with very few alternative options. As amended in 2003, direct financial assistance to the FSM, delivered through annual sector grants, will end in 2023. Prior to that date, an increasing percentage of USA aid funds will be placed in a trust, which after 2023 is intended to serve the same purpose as prior grant assistance (Gootnick, 2016). The long-term self-sufficiency of this financial structure is doubtful. A 2016 Department of Interior financial review (US Department of Interior, 2017) states a "low probability" that the trust fund status after 2023 will be equivalent to fiscal year 2023 grant aid. Thus, the FSM must navigate simultaneously the uncertain impacts of climate change and economic change. 


\section{Yap State environmental conditions}

Sharp differences across Yap's islands exist in topography, geology, and the subsequent characteristics of fresh-water storage, vegetation, and food production. Yap's MI are the peaks of an accretionary wedge located on the easternmost margin of the Philippine plate, and are surrounded by a broad fringing reef system. The underlying geology is mostly metamorphic rock and weathered volcanic breccia (Nedachi et al., 2001). Soils in the uplands are deep and have developed in residuum from volcanic materials and schists; the coasts are dominated by mangrove forests and alluvial muck soil (Smith, 1983). The islands have robust groundwater reserves, sufficient to pump approximately 1.5 million litres/day (Belt et al., 1982), which is estimated to be more than sufficient to serve a hypothetical population of at least 9,300 (Shade et al., 1992). The vegetation of the MI has been highly modified by human activity, and other than mangroves, little native forest remains; approximately $40 \%$ of the MI is covered in some type of forest (including upland, swamp, and mangrove), $26 \%$ in agroforest, $6 \%$ in secondary vegetation, and $28 \%$ in non-forest use (Falanruw et al., 1987). The inhabited atolls of the OI, on the other hand, have coralline soils and comparatively less diverse topography and vegetation. Residents of the OI must rely on shallow freshwater lenses and rainfall for drinking and terrestrial food production needs.

As might be expected, differences in local environments have led to different traditional food production strategies across Yap State. The MI developed an intensive approach that functionally divided the island into habitat zones by which rainfall is collected at the ridge, then routed and filtered through biotic communities successively less tolerant of siltation, until it is routed into near-shore streams and, ultimately, a reef channel (Falanruw, 1990, 1993). In this system, higher elevation forests transition first to grasslands with tilled ditch beds (e.g., sweet potatoes), then to shifting gardens (e.g., yams) in open canopies, then to intermittent mixed gardens in forested areas (e.g., breadfruit, Colocasia esculenta taro, herbs), and finally to coastal tree gardens and taro patches (e.g., Cyrtosperma merkusii [Hassk.] Schott, also known as Cyrtosperma chamissonis [Schott]) and 55 other food species (Falanruw, 1993; Manner \& Clark, 1993). This approach, though requiring careful management, proved to be sustainable over Yap's history (Falanruw \& Ruegorong, 2015). Reef fishing provided additional food supplies, with overexploitation prevented by strict rules regarding site access and catch limits rooted in Yap's traditional resource tenure system (Kronen \& Tafileichig, 2008).

Traditional agricultural production across the OI is similar to that in other Pacific atolls. Agroforestry is arranged in zones reflecting gradations in exposure to saltwater, saline spray, and availability of freshwater (Manner, 1993a). On larger islets, the coastal strand is dominated by coconut woodlands and agroforests (approximately $70 \%$ of total area), with mixed coconuts and breadfruit agroforests slightly more inland (approximately 30\% of total area), and the islets' interiors are typically dominated by (salt intolerant) breadfruit agroforest (less than $10 \%$ of total area) (Manner, 1993a). Both Colocasia esculenta and Cyrtosperma merkusii (Hassk.) Schott are planted in pits located near the centres of larger islets where the freshwater lens is thickest (Manner, 1993b). Additional foods come from a range of tree crops (e.g., pandanus, banana, mango, and papaya), root crops (e.g., two additional genera of taro: Alocasia and Xanthosoma; cassava, and arrowroot), and vegetable crops (e.g., beans, peppers, cabbage, etc.) (Manner, 1993a). Nearly all food production requires very careful attention to planting location and method, limited by a lack of organic matter and plant sensitivity to salinity (Manner, 1993b; Stone et al., 2000).

Observed climate changes for the FSM include increasing air and sea surface temperatures, increasing numbers of tropical storms, and increasing ocean acidification (Australian Bureau of Meteorology and CSIRO, 2014), but quantitative documentation of climate-related impacts across Yap State are sparse. Though precipitation across Yap is highly correlated with ENSO occurrence and intensity (PICEP, 2014), there has been no discernible change in Yap's average monthly precipitation since 1952 (Australian Bureau of Meteorology 
and CSIRO, 2014). On the MI, a 2013-2014 survey conducted in 117 of 120 villages indicates that saltwater intrusion, though highly spatially variable, is reported to be impacting taro patches up to, and sometimes exceeding, $5 \mathrm{~m}$ elevation (Ruegorong et al., 2016). The sensitivity of atolls, in general, to saltwater intrusion and drought is well documented (e.g., Chui \& Terry, 2015; Terry \& Falkland, 2009; Werner et al., 2017). Of particular concern is the coincident occurrence of extreme high tides, rising sea levels, and strong storm surges, potentially leading to the overtopping of atolls by saltwater (Werner et al., 2017). Within Yap State, saltwater intrusion during such an event in 2007 led to the mortality of $90 \%$ of the taro crop on the islet of Falalop, Ulithi atoll, and $75 \%$ of the taro crop on the islet of Falalop, Woleai atoll (Hezel, 2009). Thus, even without a full documentation of local-scale climate changes, it seems clear that atolls will experience the impacts sooner and more severely than will the higher-elevation MI.

Potential adaptation responses related to these impacts will also differ between the MI and OI. The MI have more land, more productive soils, and a bigger and more productive reef. Indeed, nearly all of Yap can be utilized to produce some type of traditional food (Falanruw, M., pers. comm.). In addition, the MI will benefit from having more money, more water, greater access to external resources (e.g., emergency supplies, technical, financial, and intellectual), and more political strength. The OI face an unsurprisingly narrower and less flexible path for adaptation. Some food production methods can utilize raised beds to avoid saltwater intrusion, and indeed this is already being seen in some OI locations (Falanruw, M., pers. comm.). While this may be an option for vegetable crops and some species of taro, it is not feasible for tree crops.

Another response available to OI residents is migration to the MI. OI to MI migration did increase from 1.3\% to 2\% of the OI base population between 1994 and 2000 (Yap Branch Statistics Office, 2002), with Alkire (1993) identifying access to education, healthcare, and employment as key motivations at the time. According to one key OI stakeholder, these remain more important than climate change-related concerns as to why OI residents might relocate, though he feels this is likely to change as climate impacts become more pronounced (Raigetal, L., pers. comm.). While OI populations on the MI seem clearly to be growing (i.e., four official settlement locations and other unofficial ones), government census data show the OI population residing on the OI actually increased by an annual rate of $0.4 \%$ between 2000 and 2010 (FSM Division of Statistics, 2012). Because of this uncertainty, ethnographic and demographic research specifically addressing why and to what extent OI residents are migrating is clearly needed to anticipate future social, economic, and environmental impacts.

\section{Adaptive elements of cultural heritage in Yap State}

The islands of Yap State have been occupied for perhaps over 2,500 years (Dodson \& Intoh, 1999). During that period, residents developed a complex and sustainable approach to resource management and social stability. Nunn et al. (2017) argue that historic Yapese stonework construction strategies were adaptive responses to shifting sea levels due to climatic warming and cooling events over the last millennium. Nunn et al. (2017, p. 10) primarily focused on tangible elements of Yapese heritage, e.g., Yapese men's houses (faluw) and other stoneworks such as those used with taro gardens $(m u$ 'ut), and 'intangible ones that articulate a determination to resist attempts by 'Nature' to prevent Micronesians from continuing to occupy island coasts." Their study is noteworthy because it provides a detailed examination linking cultural heritage and a people's adaptive capacity to respond to climate change impacts. It is also valuable in its focus on Yap State specifically.

We seek to complement works such as Nunn et al.'s (2017) by also emphasizing the position that intangible elements of indigenous Micronesian culture "perform in a great variety of adaptive ways" (Petersen, 2009, p. 226) that have long aided survival in such a vulnerable environment. Along with examining the traditional ecological knowledge and 
technological ingenuity islanders used (and perhaps still use) to mitigate impacts of climate events (e.g., Nunn, 2007), we feel elements of intangible cultural heritage that specifically help to create and maintain a high level of social resilience are equally important in assessments of adaptive capacity. While they may be disappearing for many reasons, traditional patterns of support are still present in varying degrees in Yap State (Krause, 2016) and certainly throughout the world in societies where group identity is valued more than individuality (c.f., Lazrus, 2015). Kinship systems, traditional sociopolitical organizations, chiefly redistribution of resources, and a variety of other forms of local knowledge that provide protocols for social interactions and practices are all strands of web-like social 'safety-nets'. Both authors have witnessed these practices following Typhoon Sudal (2004) and Typhoon Maysak (2015). The theory that cultural patterns take shape in response to ecological constraints is certainly not new and is most developed in Julian Steward's (1955) cultural ecology paradigm. Steward's materialist approach provided a groundbreaking model at the time for identifying similarities between cultures inhabiting similar environments. Our arguments here clearly echo the cultural ecology framework but differ significantly when avoiding the more generalizing tendencies common to early applications of Steward's theories.

Culturally, Yap State is best understood as comprised of two separate indigenous groups whose ancestors settled the islands at different times and most likely from different origins. Main Islanders are culturally 'Yapese' and speak a distinct Yapese language. OI residents share a 'Carolinian' cultural heritage, which is the term given to describing the indigenous inhabitants of the Caroline Islands (as well as the remote southwest atolls of Palau) with languages that are included within the Carolinian linguistic family (Ellis, 2012). To those unfamiliar, the Yapese and Carolinian cultures may appear very similar, but there are significant differences that stand out and make it very clear that Main Islanders and Outer Islanders are two distinct groups. In turn, these distinctions also factor into considerations of how both groups might rely upon traditional cultural patterns when confronting the various impacts of climate change.

\section{Relevant features of MI cultural heritage}

The traditional Yapese (i.e., MI) sociopolitical system is still largely in place and has its roots in the social values heavily influenced by the MI's past population pressures (Lingenfelter, 1975). These values were necessarily built upon the material needs of the society. On a small cluster of remote islands, perhaps nothing is more important than the efficient, sustainable use of land. Land on the MI thus holds a central importance in the daily lives of residents, both materially and symbolically. Egan (2004, p. 22) captures this importance by stating simply, "Land sustains life. Irrigated taro patches, well-tended yam gardens, and groves of coconut, betel, and breadfruit trees have long provided the people [...] with the means of their subsistence."

The MI sociopolitical system is hierarchical in organization, with a differentiating status or rank potentially assigned to every family member, estate, and village. Status is determined by, and primarily structured around, patrilineal ties to ancestral landed estates, known as tabinaw (which define the protocols of access to estate resources). Women are members of the estates they are born into, but they eventually marry into their husband's estate. The most significant areas within the tabinaw are the daef, "the stone platform upon which rests the central dwelling of the estate head" (Egan, 2004, p. 23). As Marksbury (1979) notes, a tabinaw is not simply a parcel of land, but a collection of parcels of land associated with a daef. Each of these parcels has its own productive and social value for the tabinaw, and often several parcels, such as taro patches, are found some distance away from other pieces of land associated with the estate. There exist well-defined protocols for who has rights to various parcels of land and reef tied to estates and villages so that even lower-ranked groups without resources of their own can access these areas if needed. These values inform the protocols and patterns of Yapese social organization to emphasize the importance of ensuring that the basic needs of 
all are met. They also help to bolster social resiliency, which in turn strengthens the adaptive capacity to respond to impacts associated with climate change on the islands.

While patrilineal inheritance and patrilocality form the main threads of connections, matrilineal clans are also very important strands of the Yapese webs of support. Everyone is born into their mother's clan, and "Clan membership formed a basic part of each person's social identity and indicated which historic group he or she is a part of" (Labby, 1976, p. 15). Labby's analysis interprets Yapese kinship as being a "social system arising from ongoing histories of transactions between successive exogamous matrilineal clans negotiating rights to landed estates through an exchange of service, labor, respect, and care" (Throop, 2010, p. 42). The exogamous flow of clan members through estates has meant that "People of one clan establish themselves as part of particular estate in one generation, only to pass the estate on to people of other clans in the next generation, even as their own clan progeny have left and found land elsewhere" (Egan, 2004, p. 25). This system is complex, but also highly effective at creating a wide but tightly woven web of support throughout the main islands (Krause, 2016). As with the matrilineal Carolinian culture of the OI discussed later, clan relatives provide an important source of obligated assistance on the MI when needed.

Many of the adaptive elements of the MI's intangible cultural heritage can be seen as shaped by the struggle to survive when resource availability was stressed due to demand pressures. Estimates of the MI's maximum population before European contact in 1525 range from 25,000 (Hunter-Anderson, 1983) to 40,000 (Underwood, 1969). This is at least three, and maybe even more than five, times the current population. Sherwood Lingenfelter, author of one of the seminal cultural anthropological assessments of the MI, states that Yapese culture "adapted itself to this condition of intensive population, and was organized politically and socially to operate with a large population base. (Present social values reflect these past conditions in which resources were extremely scarce and competition to obtain them intense)" (Lingenfelter, 1975, p. 6; emphasis added). The social values that took form amid the harsh realities mentioned above endure to present day (see Krause, 2016; and especially Throop, 2010).

Though the current population is significantly smaller than past maximum levels, basic social norms and values remain firmly in place. For example, respect (liyeor) is a key value that Yapese see as fundamental to their social order (Krause, 2016). As one local mentioned during a 2014 interview, living on Yap is "like being on a small boat in the middle of the ocean with people you have to get along with" (Krause, 2015, p. 59). Another central value is suffering (gaafgow), which reflects, among other things, the struggle for survival and the hard work expected of individuals in this collective struggle (Throop, 2010). This core value also reveals the deep respect Yapese hold for ancestors who lived and died during many tragic periods when they faced starvation and extreme hardships. Memorialized in chants and dances, stories of suffering during Japan's Second World War military occupation or others of the aftermath following major destruction from typhoons live on as they are retold to newer generations. The many accounts of enduring the suffering of past hardships, struggles to survive, and eventually rebuilding their lives provide a strong oral tradition of resiliency which cannot be ignored in the analysis of Yap's adaptive capacity to respond to current and future climate change related threats.

Preserving elements of intangible cultural heritage associated with the knowledge and protocols that reaffirm the traditional Yapese sociopolitical order is still a priority on the MI (Krause, 2016). Risking simplification, it is respect (liyeor) and knowing one's obligations (as defined by your estate and matriclans) within the family, within the village, and throughout the islands that is of vital importance to preserve for many Main Islanders. Krause (2016) concluded that the fear of losing these parts of their heritage is especially worrisome since they are the strands that hold together their strong webs of support. He posits that the anxiety fueling Main Islander discourse on cultural heritage preservation may be resulting from their transition from a traditional, subsistence-based lifestyle (based in values of reciprocity, redistribution, and care for all) into a modern (but uncertain) market economy where these 
communal values are less important. If it is true that Main Islanders are prioritizing the preservation of adaptive features of their culture that create and maintain a system of built-in obligations toward one another for the common good of all, these same intangible forms of heritage are likely to hold value in helping to mitigate vulnerabilities to climate change impacts as they become more observable and pressing.

\section{Relevant features of OI cultural heritage}

One of the most significant adaptive features within Carolinian cultural heritage is its matrilineal descent system, organized around numerous exogamous matriclans dispersed throughout the islands. This system is held together through a shared cosmology in which clan lineages directly link present populations to their ancestral origins. Petersen (2009, p. 226) notes, "Micronesian matrilineal clans and lineages perform in a great variety of adaptive ways." These cultural features facilitate resiliency against catastrophic events such as major typhoons that can temporarily wipe out essential resources on low-lying islands. This is largely because dispersed matriclans provide direct linkages between clan relatives scattered hundreds of miles throughout the numerous habitable islands in the region. In effect, were a typhoon to destroy food resources and available freshwater supplies on an island, affected residents would be able to sail to neighbouring islands and seek refuge and assistance from their fellow clan members, who would be obligated to take them in.

Another important cultural feature among Carolinian groups (and, indeed, throughout the Pacific, including the main islands of Yap) is the widespread practice of adoption. Within Micronesia, Marshall (1999) concludes that on many islands, half or more children are adopted. Rubinstein (1979) calculated a 92\% adoption rate on the Yapese outer island of Fais. As with the matrilineal descent system, the high prevalence of adoption on the islands can be viewed as strategically adaptive to the material demands present for small-island societies. While noting that adoptions on the outer islands of Chuuk and Yap State primarily occur within communities on the same islands, Rauchholz (2012, pp. 130-131) adds that adoption has been a "means of establishing connections to other islands to provide an additional source of support in times of need [...] [and] these ties were often crucial for survival when storms destroyed an island and survivors needed to relocate." Furthermore, along with establishing and maintaining social bonds between families and groups and providing flexibility in the passing down of land rights, the accepted practice of adoption also makes it easier for local populations to sustainably manage the production, distribution, and consumption of their very limited resources. If a household does not have enough children to help with current and future subsistence activities, they can seek to add family members through adoption. Similarly, if resources are being strained because a household is too large, through adoption, family size can be adjusted to a more sustainable level. As Rauchholz (2012, p. 129) thus observes, "residence patterns of adopted children generally reflected what islanders viewed as being optimal ways of fulfilling everyone's needs." The flexibility manifested in Carolinian cultural heritage through lineage and descent patterns, adoption practices, and many other interconnected intangible features such as traditional navigation knowledge, must be considered when assessing local adaptive capacities to climate change impacts.

The sawei system

While culturally distinct, the Main Islanders and Outer Islanders in Yap State share a deep, centuries-old relationship with enduring connections. Oral histories from both cultures depict a relationship that led some early scholars (see Petersen, 2000, for debates on this subject) to conclude a 'Yapese Empire' once existed, in which the MI's sphere of power extended vast distances to the east, and Outer Islanders were subordinate to Main Islanders. While this characterization has been qualified (Petersen, 2000, 2009), there are interconnecting features of Yapese and Carolinian cultural heritage linking the two groups that arguably developed as adaptations for survival in response to the extreme environmental vulnerabilities that have 
long existed on their islands (Petersen, 2009). A prime example is the sawei system, which historically existed as a "bicultural system of tribute offerings, gift exchange, and disaster relief' between MI and OI cultures (Hunter-Anderson \& Zan, 1996, p. 1). Though the structured tribute canoe processionals defining the sawei system were halted decades ago, the institution's legacy as it once was, still shapes the relationship between MI and OI people.

The former practice of sawei can be seen as an adaptation of mutual reciprocity between and among groups of people. The practice involved hundreds of miles of voyaging from affiliated islands as far away as Namonuito, Pulap, and Houk (within Chuuk State territory today). Following strict protocols, voyaging canoes stopped along a series of other islands, which incrementally joined the caravan of canoes, tribute, and people sailing to the MI to present their offerings to the two traditionally affiliated villages of Gachpar and Wonyan (in Gagil Municipality). Having ceased over a century ago under the German administration, the sawei system provided these villages added status within the MI political order through the acquisition by their chiefs of various forms of prestigious tribute such as lavalavas (i.e., handwoven rectangular pieces of fabric originally made from banana fibres) and rare shells (which in turn became high-valued items within the traditional MI exchange system). In exchange for their fealty and proper observance of customary tribute protocols, the OI visitors were presented valuable items unavailable on their resource-poor islands. Along with numerous types of needed foods, they were also given items such as lumber, tools, imported manufactured items, and pigments and turmeric, which had ceremonial value (HunterAnderson \& Zan, 1996).

It is natural to assume that in hierarchical societies that have strictly defined class distinctions, groups such as the Outer Islanders who are among the lowest in ranking in the Main Islander hierarchy would be much more vulnerable to crises, which push resource scarcity to its limits. This does not appear to be the case in Yap State when considering the adaptive features of cultural heritage found in such forms as the sawei in the past and other extant cultural patterns presented above. Once again, the values upon which the traditional society was built have formed a society that strives to ensure everyone obtains what they need to survive. As one of the Yapese participants in Krause's (2016, p. 346) study puts it:

The [Yapese Main Island] system is structured in a way that nobody is left behind. Nobody has become homeless because nobody can take care of that person. No child is left without somebody to care for or to look after the interests of his wellbeing and other things.

This view toward the care of everyone also extends to the Carolinians who have at times been dependent upon assistance from Main Islanders. Krause (2016) notes in his research that Main Islanders often describe their relationship to the Outer Islanders as being symbolically equivalent to that of parents towards their children. As told to Krause, the 'parent' villages of Gachpar and Wonyan (more specifically, it is certain estates within these villages which hold the title) are obligated to help their 'children' from the OI when assistance is requested. This obligation reportedly even supersedes that toward their natal families. And while it is impossible to quantify today how significant sawei protocols of obligatory support actually were so long ago, anthropologists have generally concluded that "in terms of value or quantity of things exchanged, the Outer Islanders received from the Yapese far more than they gave" (Hunter-Anderson \& Zan, 1996, p. 4). For those Carolinians affiliated with the practice, as a customary "insurance policy for survival" (Alkire, 1977, p. 52) the sawei system thus widened the base of accessible resources in times of need even further than the already present chiefly redistribution, matrilineal clans, and extended kin networks. 


\section{Conclusion}

Four main points arise from this study. First and fundamentally, this study affirms the notion that to fully understand the adaptive capacity of small islands to the impacts of climate change, it is critical to examine each island's specific geological, ecological, socioeconomic, and cultural environments. This reinforces the conclusions of researchers (e.g., Allen, 2015; Farbotko \& Lazrus, 2012; Stratford et al., 2013) that SIDS in the Pacific differ in their perceptions and responses to vulnerability and food insecurity, even if they share commonalities in their isolation, small size, and other resource constraints. Small island cultures, over the millennia of their existence, have had to continually (and quickly) develop sustainable responses to a dynamic environment, the most recent example of which is ongoing climate change. For these reasons, the vulnerabilities and adaptive capacities within the separate islands of Yap State must be seen as deeply rooted in the environmental and cultural components of their shared heritage. Allen's (2015, p. 1341) conclusions following an examination of Malo Island (Vanuatu) are equally valid for Yap State: "[Islanders' responses to climate change] demonstrate the importance of $[\ldots]$ adaptive capacity of traditional practices and institutions [...] to the sustainability of social-ecological systems."

Indigenous OI and MI cultural groups of Yap State have developed complex protocols relating to resource management, social structure, and land tenure, as well as intra- and interisland norms of reciprocity. Inter-family and inter-village support networks promote social resilience, aiding adaptive capacity to environmental and other pressures. On Yap's MI, the interweaving of matrilineal and patrilineal rights and obligations tied to food production and exchange can mitigate the localized impacts of sea-level rise in vulnerable coastal villages. Main Islander views of climate change are thus tempered by traditional (and unwritten) rights to other land and food production mechanisms.

This strong communal support system makes precise evaluation of the MI's adaptive capacities problematic. Also complicating matters is the reality that modern threats (e.g., economic, political) and opportunities (e.g., scientific) may transform the cultural ecology of the MI with regards to how residents adapt to and manage environmental threats. One example of this is the recent effort by MI residents to integrate traditional food production knowledge with modern geospatial science and technology to develop a watershed-based approach to food security.

Second, if climate change continues to stress the habitability of Yap's OI, these residents will very likely rely upon traditional support networks and relocate to Yap's MI, which have a greater capacity to adapt given their more diverse environmental conditions. It has been over a century since the formal inter-island voyages and exchanges that defined the sawei system have taken place. However, the values and protocols embedded within the sawei relationship between the Yapese and their Carolinian neighbors, including those that facilitate the movement of people and goods between the OI and MI, are still influential today. The sawei relationship, even more than modern politics, dictates that Carolinians are not treated as foreigners. This has made it easier for Carolinians choosing to move to the MI for economic and educational opportunities, healthcare, and access to a variety of government services. This same environment of support will surely be depended upon as more Carolinians relocate to the MI due to continued climate change impacts.

Third, it is difficult to foresee the range of social, economic, and ecological impacts that increased migration from the OI to the MI will have upon Yap State. As the OI become less habitable, more and more OI residents will become permanent residents on the MI, not temporary visitors as some are today. They will be without land (therefore without traditional social status), without jobs or income, and hungry. If Yapese Main Islanders see themselves as having a near parental responsibility to OI residents, the question also arises of how this symbolic view towards obligations of support may be challenged and ultimately change, as 
conditions worsen. The indigenous MI population will almost certainly attempt to assume some of the responsibility for housing, supporting, and feeding these new arrivals, but the strategies and likelihood of success are not clear. While benefitting from the flexibility in adaptive capacity due to its being a high-elevation island, the MI do still face a degradation in food production capacity and long-term declines of reef health. The four planned locations for OI settlement will concentrate demands of food, shelter, and water. Provision of the latter two is not expected to be difficult, but access and use of land parcels for food production have never been mapped. Protocols and cultural norms that have long served to create social resiliency for both groups will be tested.

Finally, working within the analytical framework described above, four clear lines of future research within Yap State present themselves. The need for each is consistent with others' findings (e.g., Nunn, 2009), and directly responds to Nurse et al.'s (2014) call for greater depth of investigation within island states. First, more ethnographic work is needed to quantitatively assess how many residents are now displaced because of climate change impacts on their home islands. Second, qualitative fieldwork is also required to assess the cultural consequences of this migration and how, for instance, Yapese and Carolinians are relying on traditional values and protocols to adapt to their changing realities. While the sawei practice may be dormant, its heritage still informs views and values toward ensuring the needs of all are met. The degree to which these customs and protocols are influencing adaptive capacity for both groups is entirely unknown. Third, more research is needed to provide a clear understanding of how elements of Yapese and Carolinian cultural heritage can continue to provide a social 'safety net' at a time when the region is becoming ever-more connected to global flows of people, goods, technologies, and ideas. If it is shown that these elements directly or indirectly increase adaptive capacity, then efforts to safeguard their loss would seem to be a valuable option worth considering. Finally, there are considerable questions regarding the net effect of economic aid from the US. Does this assistance help Yap State (and all of FSM) through the purchase of technology, food, jobs, and construction of infrastructure? Or, does financial assistance effectively undermine traditional culture and the longstanding adaptive capacity developed over millennia? With the projected rates of sea-level rise and other climate-related changes in Micronesia, time is limited to begin pursuing the answers.

\section{References}

Alkire, W. (1977). An introduction to the peoples and cultures of Micronesia. Menlo Park: Cummings.

Allen, M.G. (2015). Framing food security in the Pacific Islands: empirical evidence from an island in the Western Pacific. Regional Environmental Change, 15(7), 1341-1353. https://doi.org/10.1007/s10113-014-0734-5

Australian Bureau of Meteorology and CSIRO (2014). Climate variability, extremes and change in the western tropical Pacific: New science and updated country reports. Pacific-Australia climate change science and adaptation planning program technical report, Australian Bureau of Meteorology and Commonwealth Scientific and Industrial Research Organisation, Melbourne.

Barnett, J., \& Campbell, J. (2010). Climate change and small island states: power, knowledge, and the South Pacific. Earthscan.

Belt, Collins, \& Associates (1982). Yap island water well development: January to March 1982. Honolulu: T. Nance.

Cazenave, A., \& Remy, F. (2011). Sea level and climate: measurements and causes of changes. WIREs Climate Change, 2(5), 647-662. https://doi.org/10.1002/wcc.139

Central Intelligence Agency (2017). Federated States of Micronesia. CIA world factbook. https://www.cia.gov/library/publications/the-world-factbook/geos/fm.html 
Chui, T.F.M., \& Terry, J.P. (2015). Groundwater salinisation on atoll islands after stormsurge flooding: modelling the influence of central topographic depressions. Water and Environment Journal, 29(3), 430-438. https://doi.org/10.1111/wej.12116

Dodson, J.R., \& Intoh, M. (1999). Prehistory and palaeoecology of Yap, Federated States of Micronesia. Quaternary International, 59(1), 17-26. https://doi.org/10.1016/S10406182(98)00068-8

Egan, J.A. (2004). Keeping-for-giving and giving-for-keeping: value, hierarchy, and the inalienable in Yap. In C. Werner \& D. Nell (Eds.) Values and valuables: from the sacred to the symbolic (pp. 21-48). Walnut Creek: Altamira.

Ellis, S.J. (2012). Saipan Carolinian, one Chuukic language blended from many. PhD dissertation, University of Hawaii.

Falanruw, M.C. (2016). Personal communication, 15 June.

Falanruw, M.C. (1990). Traditional adaptation to natural processes of erosion and sedimentation on Yap island. Proceedings of the Fiji Symposium, June 1990.

Falanruw, M.C. (1993). Taro growing on Yap. Yap Institute of Natural Science. Colonia: Yap, Federated States of Micronesia.

Falanruw, M.C., \& Ruegorong, F. (2015). Dynamics of an island agroecosystem. In M.F. Cairns (Ed.) Shifting cultivation and environmental change: indigenous people, agriculture and forest conservation (pp. 367-386). London \& New York: Routledge.

Falanruw, M.C., Whitesell, C.D., Cole, T.G., MacLean, C.D., \& Ambacher, A.H. (1987). Vegetation survey of islands of Yap, Federated States of Micronesia.

Farbotko, C., \& Lazrus, H. (2012). The first climate refugees? Contesting global narratives of climate change in Tuvalu. Global Environmental Change,22(2), 382-390. https://doi.org/10.1016/j.gloenvcha.2011.11.014

Federated States of Micronesia (FSM), Division of Statistics (2012). Summary analysis of key indicators: from the FSM 2010 census of population and housing. Palikir, Pohnpei.

Gootnick, D. (2016). Issues associated with implementation in Palau, Micronesia, and the Marshall Islands. Washington, DC: Government Accountability Office.

Hezel, F. (2009). High water in low atolls. Micronesian Counselor, 15 March. http://www.micsem.org

Hunter-Anderson, R.L. (1983). Yapese settlement patterns: An ethnoarchaeological approach. Agana, Guam: Pacific Studies Institute.

Hunter-Anderson, R. \& Zan, Y. (1996). Demystifying the sawei, A traditional interisland exchange system. ISLA: A Journal of Micronesian Studies, 4(1), 1-45.

Keener, V.W., Marra, J.J., Finucane, M.L., Spooner, D., \& Smith, M.H. (2012). Climate change and Pacific islands: Indicators and impacts: executive summary of the 2012 Pacific Islands Regional Climate Assessment (PIRCA).

Krause, S.M. (2015). The art of communication in Yap, FSM: traditional forms of respectful interactions. In S. Lee (Ed.) Traditional knowledge and wisdom: themes from the Pacific islands (pp. 46-59). ICHCAP: UNESCO.

Krause, S.M. (2016). The production of cultural heritage discourses: Political economy and the intersections of public and private heritage in Yap State, Federated States of Micronesia. PhD Dissertation, University of South Florida.

Kronen, M., \& Tafileichig, A. (2008). Traditional rights and management of Yap's coastal fisheries and the role of fisherwomen. SPC Women in Fisheries Information Bulletin, 18, 21-25.

Labby, D. (1976). The demystification of Yap, dialectics of culture on a Micronesian island. Chicago: University of Chicago Press.

Lazrus, H. (2015). Risk perception and climate adaptation in Tuvalu: a combined cultural theory and traditional knowledge approach. Human Organization, 74(1), 52-61. https://doi.org/10.17730/humo.74.1.q0667716284749m8 
Lingenfelter, S.G. (1975). Yap, political leadership and culture change in an island society. Honolulu: University Press of Hawaii.

Manner, H.I. (1993a). A review of traditional agroforestry in Micronesia. Proceedings of the workshop on research methodologies and applications for Pacific island agroforestry, 140, 32-36.

Manner, H.I. (1993b). Taro (Colocasia esculenta (L.) Schott) in the atolls and low islands of Micronesia. In L. Ferentinos (Ed.) Proceedings of the sustainable taro culture for the Pacific conference, September 24-25, 1992 (pp. 88-100). Honolulu: University of Hawaii.

Manner, H.I., \& Clarke, W.C. (1993). Traditional agroforestry in the high islands of Micronesia. In W.C. Clarke (Ed.) Agroforestry in the Pacific islands: systems for sustainability (pp. 124-130). Tokyo: United Nations University Press.

Marksbury, R. (1979). Land tenure and modernization in the Yap islands. PhD thesis, Tulane University, New Orleans.

Marshall, M. (1999). 'Partial connections': kinship and social organization in Micronesia. In R.C. Kiste \& M. Marshall (Eds.) American anthropology in Micronesia: an assessment (pp. 107-143). Honolulu: University of Hawaii Press.

Nedachi, M., Maeda, T., Shigeyoshi, R., Inoue, A., Shimada, K., Higashi, M., Habano, A., Azuma, T., \& Hatta, A. (2001). Geological environments of Yap islands, Micronesia. The progress report of the 1999 survey of the research project Social Homeostasis of Small Islands in an Island-Zone: Yap Proper, Micronesia and Islands in Southern Japan. Kagoshima University Research Center for the Pacific Islands.

Nunn, P.D. (2013). The end of the Pacific? Effects of sea level rise on Pacific Island livelihoods. Singapore Journal of Tropical Geography, 34(2), 143-171.

Nunn, P.D. (2009). Responding to the challenges of climate change in the Pacific islands: management and technological imperatives. Climate Research, 40(2-3), 211-231. https://doi.org/10.3354/cr00806

Nunn, P.D. (2007). Climate, environment and society in the Pacific during the last millennium. Amsterdam: Elsevier. https://doi.org/10.1016/S1571-9197(07)06001-6

Nunn, P.D., Runman, J., Falanruw, M., \& Kumar, R. (2017). Culturally grounded responses to coastal change on islands in the Federated States of Micronesia, northwest Pacific Ocean. Regional Environmental Change, 17(4), 959-971.

Nurse, L.A., McLean, R.F., Agard, J., Briguglio, L.P., Duvat-Magnan, V., Pelesikoti, N., Tompkins, E., \& Webb, E. (2014). Small islands. In V.R. Barros, C.B. Field, D.J. Dokken, M.D. Mastrandrea, K.J. Mach, T.E. Bilir, M. Chatterjee, K.L. Ebi, Y.O. Estrada, R.C. Genova, B. Girma, E.S. Kissel, A.N. Levy, S. MacCracken, P.R. Mastrandrea, and L.L. White (Eds.) Climate change 2014: Impacts, adaptation, and vulnerability. Part B: Regional Aspects. Contribution of Working Group II to the Fifth Assessment Report of the Intergovernmental Panel on Climate Change (pp. 1613-1654). Cambridge, UK, \& New York, NY: Cambridge University Press.

Pacific Islands Climate Education Partnership (PICEP) (2014). Climate change in the Federated States of Micronesia. Honolulu, Hi: Pacific Resources for Education and Learning.

Park, S.E., Marshall, N.A., Jakku, E., Dowd, A., Howden, S.M., Mendham, E., \& Fleming, A. (2012). Informing adaptation responses to climate change through theories of transformation. Global Environmental Change, 22(1), 115-126. https://doi.org/10.1016/j.gloenvcha.2011.10.003

Petersen, G. (2000). Indigenous island empires: Yap and Tonga considered. The Journal of Pacific History, 35(1), 5-27.

Petersen, G. (2009). Traditional Micronesian societies: Adaptation, integration and political organization. Honolulu: University of Hawaii Press. https://doi.org/10.21313/hawaii/9780824832483.001.0001 
Raigetal, L. (2016). Personal communication, 21 December.

Rauchholz, M. (2012). Discourses on Chuukese customary adoption, migration, and the laws of state(s). Pacific Studies, 35(1/2), 119-143.

Rubinstein, D.H. (1979). An ethnography of Micronesian childhood: contexts of socialization on Fais Island. PhD Dissertation, Stanford University.

Ruegorong, F., Falanruw, M., \& Perkins, R. (2016). Saltwater intrusion into near-shore taro patches on Yap, Federated States of Micronesia. Unpublished data.

Shade, P.J., Anthony, S.S., \& Takasaki, K.J. (1992). Ground water resources reconnaissance of the Yap main islands, Federated States of Micronesia. Water Resources Investigation Report, 90-4074. Honolulu.

Smit, B., Pilifosova, O., Burton, I., Challenger, B., Huq, S., Klein, R.J.T., Yohe, G., Adger, N., Downing, T., Harvey, E., Kane, S., Parry, M., Skinner, M., Smith, J., \& Wandel, J. (1999). Adaptation to climate change in the context of sustainable development and equity, contribution of working group II to the third assessment report of the intergovernmental panel on climate change: Adaptation to climate change in the context of sustainable development and equity. Cambridge: Cambridge University Press.

Smith, C. (1983). Soil survey of islands of Yap, Federated States of Micronesia. Washington, DC: United States Department of Agriculture.

Steward, J. (1955). Theory of culture change: the methodology of multilinear evolution. Urbana: University of Illinois Press.

Stone, E.L., Migvar, L., \& Robison, W.L. (2000). Growing plants on atoll soils (UCRL-LR-137517). Livermore: Lawrence Livermore National Lab. https://doi.org/10.2172/756838

Storlazzi, C.D., Edwin, P.L.E., \& Berkowitz, P. (2015). Many atolls may be uninhabitable within decades due to climate change. Scientific Reports, 5, 14546. https://doi.org/10.1038/srep14546

Stratford, E., Farbotko, C., \& Lazrus, H. (2013). Tuvalu, sovereignty and climate change: Considering Fenua, the archipelago and emigration. Island Studies Journal, 8(1), 67-83.

Terry, J.P., \& Falkland, A.C. (2009). Responses of atoll freshwater lenses to storm-surge overwash in the Northern Cook Islands. Hydrogeology Journal, 18(3), 749-759. https://doi.org/10.1007/s10040-009-0544-x

Throop, C.J. (2010). Suffering and sentiment: exploring the vicissitudes of experience and pain in Yap. Berkeley: University of California Press.

Timmermann, A., McGregor, S., \& Jin, F.F. (2010). Wind effects on past and future regional sea level trends in the southern Indo-Pacific. Journal of Climate, 23(16), 4429-4437. https://doi.org/10.1175/2010JCLI3519.1

Underwood, J.H. (1969). Preliminary investigations of demographic fea-tures and ecological variables of a Micronesian island population. Micronesica, 5(1), 1-24.

United Nations (1994). Report of the global conference on the sustainable development of small island developing states. Document A/CONF.167/9, Global Conference on the Sustainable Development of Small Island Developing States. Bridgetown: United Nations.

United Nations Framework Convention on Climate Change (UNFCCC) (2005). Climate change: Small island developing states. Bonn: Climate Change Secretariat.

U.S. Relations with the Federated States of Micronesia (n.d.). In U.S. bilateral relations fact sheets. https://www.state.gov/r/pa/ei/bgn/1839.htm

Werner, A.D., Sharp, H.K., Galvis, S.C., Post, V.E.A., Jacovovic, D., Bosserelle, A., \& Sinclair, P. (2017). Hydrogeology and management of freshwater lenses on atoll islands: review of current knowledge and research challenges. Journal of Hydrology, 551, 819844. http://dx.doi.org/10.1016/j.jhydrol.2017.02.047

Yap Branch Statistics Office (2002). Yap State census report: 2000 FSM census of population and housing. Colonia, Yap: Division of Statistics, Department of Economic Affairs.

US Department of Interior (2017). Fiscal year 2016 annual report. Washington, DC: US Government. 